\title{
EVALUATION OF MARGINAL BONE LOSS AFTER IMMEDIATE IMPLANT PLACEMENT IN MAXILLARY ESTHETIC ZONE WITH CORAL BONE VERSUS XENOGRAFT (RANDOMIZED CLINICAL TRIAL)
}

\author{
Amro Abdelaal Abdelhakim Elbahkiri* , Ragia Mohamed Mounir ${ }^{* *}$ and Mohamed Mounir***
}

\begin{abstract}
Aim: The aim of the study is to evaluate marginal bone loss using coral bone graft which is a xenograft of marine origin versus xenograft of bovine origin in immediate implant placement in maxillary esthetic zone as a gap filling material.

Materials and Methods: Ten patients were participated in this study ( 3 males and 7 females), with a mean age of 34 years having non restorable single or multiple maxillary anterior teeth (18 fresh extraction sockets were conducted in the study). patient's sockets were divided randomly and equally into 2 groups : GroupA(control group): included 9 extraction sockets in 5 patients (one male and 4 females) which recived immediate post extraction implant placement with xenograft between the residual labial bone and implant surface. Group B (study group): included 9 extraction sockets in 5 patients( 2 males and 3 females) which received immediate post extraction implant placement with coral bone between the residual labial bone and implant surface. Cone beam CT was taken immediately post operative and 4 months postoperatively to measure the amount of marginal bone loss in each group and then the percentage of bone loss in each group.
\end{abstract}

Results: Wound healing was uneventful in all patients without any signs of infection or wound dehiscence, Results showed : The percentage of 4 months postoperative vertical bone loss of the control group was $7.8 \%$ and the standard deviation was 4.24 . The percentage of 4 months postoperative vertical bone loss of the study group was $7.36 \%$ and the standard deviation was 3.16 . The difference between the percentages of 4 months postoperative bone loss between both groups was not statistically significant $(\mathrm{P}$ value $=0.807)$

Conclusion: The amount of marginal bone loss in both groups was small yet it was statistically significant, the marginal bone loss in group A (with xenograft) was more than group B (with coral bone) but it was not statistically significant.

\footnotetext{
* Master Degree Of Implantology, Faculty Of Dentistry, Cairo, Egypt

** Professor Of Oral And Maxillofacial Surgery, Faculty Of Dentistry, Cairo, Egypt

*** Lecturer of Oral And Maxillofacialsurgery, Facultyof Dentistry, Cairo, Egypt
} 


\section{INTRODUCTION}

Immediate implant placement protocol was introduced to clinical practice since 1978 (Schulte et al 1978) $)^{(\mathbf{1})}$ and has the advantages of better esthetics, reduction in the number of surgeries (one surgery is needed) and reduction in the time of treatment so it is more suitable and comfortable for patients (M. Esposito et al 2010) $^{(2)}$.

Coral bone has a structure which is similar to that of cancellous bone, its mechanical properties is similar to that of bone and it consists of high content of calcium carbonate scaffolds that has the advantages of being biodegradable, biocompatible and osteoconductive, they act as a carrier for growth factors and allow cell attachment, growth, spreading, differentiation and has been found to be effective bone graft (Demers et al 2002) ${ }^{(3)}$. Over the past decade many investigators have tried to define the structure of the implant-bone interface by the use of a gentle surgical technique. After the bone drilling and the placement of dental implants, a sequence of cellular and molecular events initiates which represents a combined response of wound healing. The effect of elevated temperature generated during the surgical preparation for implant placement causes denatured of alkaline phosphatase and slowed down of bone healing. Necrosis as a result of elevated temperatures has been previously reported in the literature.(Scarano et al., 2011) ${ }^{(4)}$.

Xenografts are one of the most successful and widely used grafting materials nowadays as a replacement for autogenous bone grafts. Studies showed that xenografts are very successful because of their osteoconductive properties, their density which provides stabilization to the graft and implant and they supply the necessary minerals for bone formation as xenograft don't resorb completely (Baghban AA et al 2009)(5). Xenografts undergoes deprotienaization by heating to eliminate the allergic reactions and risk of disease transmission (Murugan et al 2003) $^{(6)}$.
The maxillary esthetic zone is a very critical area for immediate implant placement because of the high esthetic requirements in this area. Debates still exist whether to graft the gap between the implant and bone or not and if we are going to graft which grafting material is the best to be used, so the aim of this study is to evaluate marginal bone loss using coral bone graft versus xenograft in the jumping gap after immediate implant placement in the maxillary esthetic zone .

The aim of the study is to evaluate marginal bone loss using coral bone graft which is a xenograft of marine origin versus xenograft of bovine origin in immediate implant placement in maxillary esthetic zone as a gap filling material

\section{MATERIALS AND METHODS}

Ten patients were participated in this study (3 males and 7 females), with a mean age of 34 years having non restorable single or multiple maxillary anterior teeth. They were selected from the outpatient clinic of the oral implantology - Faculty of Dentistry - Cairo University.

\section{Patient grouping:}

Eligible patient's sockets were divided randomly and equally into 2 groups

Group A (control group): included 9 extraction sockets in 5 patients (one male and 4 females) who received immediate post extraction implant(Dual ${ }^{\circledR}$ Titan Industries Egypt) placement with xenograft of bovine origin (Bio-Oss ${ }^{\circledR}$ Geistlich Pharma Switzerland) between the residual labial bone and implant surface.

Group B (study group): included 9 extraction sockets in 5 patients ( 2 males and 3 females) who received immediate post extraction implant(Dual Implant Titan Industries Egypt ${ }^{\circledR}$ ) placement with coral bone which is a xenograft of marine origin (Novocor plus ${ }^{\circledR}$ B\&B Dental Italy) between the residual labial bone and implant surface. 
- 18 fresh extraction sockets were conducted in the study

\section{Preoperative preparation:}

- A thorough preoperative assessment of all patients was carried out including history taking, clinical examination and radiographic examination.

\section{History}

Each patient was interviewed to obtain a comprehensive history. The collected data was documented in each patient's diagnostic sheet.

\section{Clinical assessment}

- Visual examination and palpation of the entire oral and para-oral tissues to ensure right patient selection.

- All patients received full mouth scaling and root planning followed by proper oral hygiene instructions.

\section{Preoperative radiographic examination}

- Periapical radiographs were taken to detect the bony level around teeth and detect any intrabony lesion in area of interest (performed under standardized conditions).

- CBCT to detect labio-palatal bone width and condition of the labial plate and bone height and to evaluate proximity to vital structures. The vertical dimension of each implant site could be measured accurately in the reformatted cross sectional images (fig.1-1').

\section{Surgical procedures (for both groups A \& B):}

Infiltration local anaethesia technique was used for extraction and immediate implant placement.

An atraumatic protocol was followed during tooth extraction. A sulcular incision line with reflection in the area of immediate implant placement.
The extraction started using a periotome to clear the tissues around the root and to luxate the tooth. Then a forceps was used to deliver the tooth out of its socket using gentle extraction movements to preserve buccal plate of bone. The fresh extraction socket was irrigated with saline to remove any hard or soft debris that may be present after the extraction.

The integrity of the extraction socket was checked using an osteotomy probe. If any dehiscence or fenestration defects were found, the case was excluded from the study.

- The implant was removed from its sterile package and held using the attached plastic carrier, placed into the prepared socket using fixture driver and screwed manually until a resistance is met.

- After that the torque wrench ratchet was attached to complete the seating of the implant into its final position, with the platform lower than the bone level by 1-2 mm and the apex of the implant at least $2 \mathrm{~mm}$ beyond the socket base to gain primary stability.

- Then the primary stability was verified to be not less than $25 \mathrm{~N} / \mathrm{cm}$, the primary stability of each implant was measured using torque wrench ratchet (Dual torque ratchet), Then the cover screw was placed on the top of the implant using the screw driver.

- In the study group: implant was inserted in the extraction socket bodily palatal with coral bone for augmentation between the implant and the labial plate of bone.

- In the control group: implant was inserted in the extraction socket bodily palatal with xenograft for augmentation between the implant and the labial plate of bone.

- Jumping gap was measured intra-operative using a periodontal probe or a caliper after implant 
- The flap was copiously irrigated with saline in preparation for closure.

- Gel foam was placed over the graft in both groups to keep the graft in place

- The flap was closed using interrupted 4/0 prolene sutures.

Study group: Case number 1 (patient number 3 in the study group -35years old male patient):
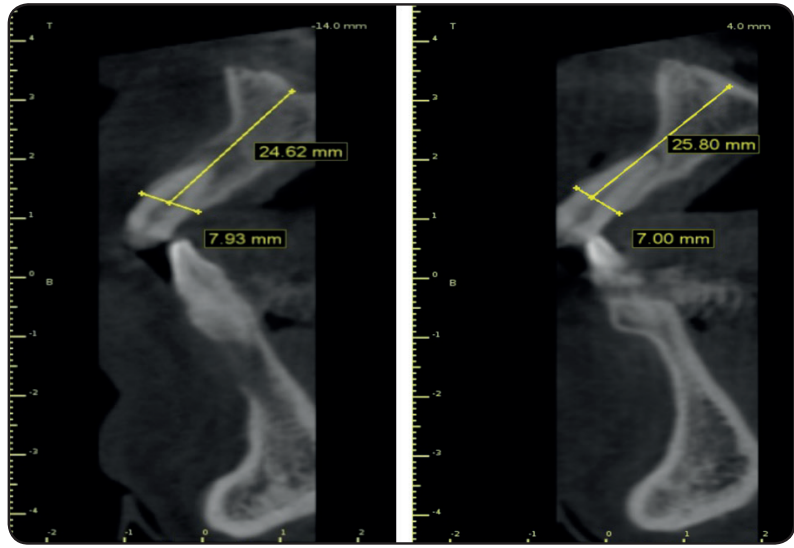

Fig. (1) CBCT showing the calculation of the vertical and horizontal dimensions of the ridge in a preoperative view.

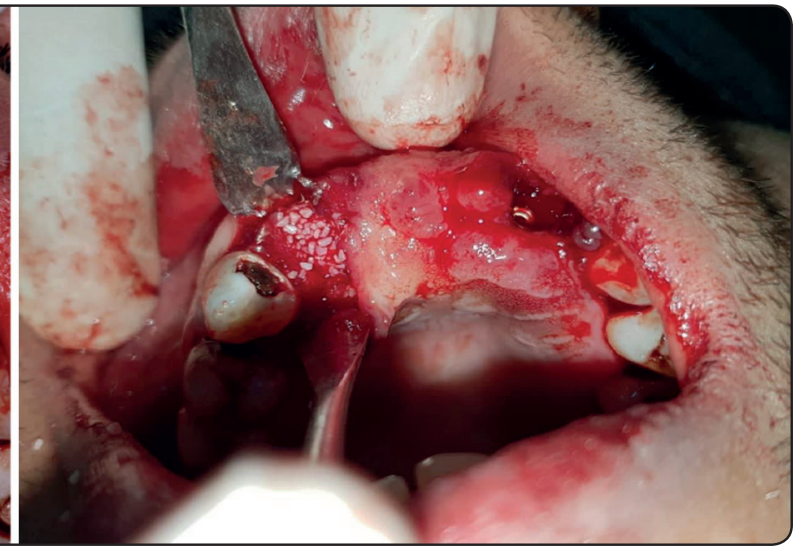

Fig. 2 \& 3: photograph showing Implants insertion bodily palatal in the extraction socket followed by measurement of the jumping gap distance and coral bone placement between the implant surface and the residual labial bone (patient number 3 in the study group)

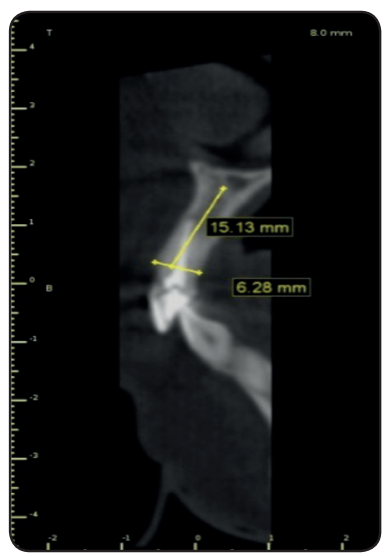

Control group: Case number 2(patient number 2 in the control group-37 years female patient):

\section{Post-operative care:}

- Post-operative medications were prescribed as follows: amoxicillin/clavulanic acid tablets 1 gm (Augmentin ${ }^{\circledR}$ GlaxoSmithKline United Kingdom) every 12 hours for 7 days, diclofenac potassium $50 \mathrm{mg}$ (Cataflam ${ }^{\circledR}$ Novartis Switzerland) every 8 hours for 4 days. 


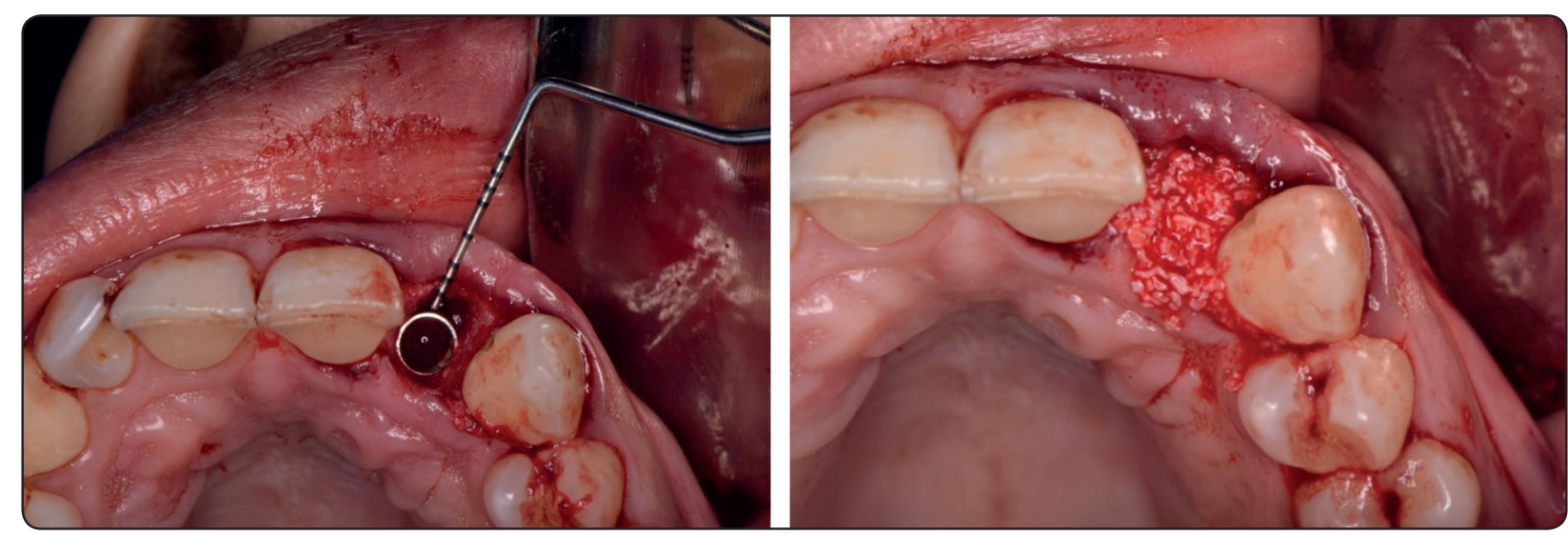

Fig. 2 \& 3': photograph showing Implant insertion bodily palatal in the extraction socket followed by measurement of the jumping gap distance and xenograft placement between the implant surface and the residual bone . (patient number 2 in the Control group)

- Post-operative instructions were explained to the patients as follows: Ice packs for 10 minutes every 30 minutes for 24 hours, strict oral hygiene measures in the form of regular use of the toothbrush and chlorhexidine mouth (Chlorhexidine mouth wash ${ }^{\circledR}$ HealthPoint United Kingdom) starting the day after the surgery, The patients were followed up after 1 week and then every 2 weeks.

- Immediate postoperative cone beam C.T was taken the day after surgery then 4 months to measure the amount of crestal bone loss.

\section{Calculation and standardization of the amount of crestal bone loss:}

The implant was used as a reference by adjusting the cross-sectional and panoramic long axis in the centre of the implant and bisecting it. On the crosssectional view, a line was drawn just parallel to the implant, starting at the crest of the labial plate of bone and ending at the apical level of the implant; height was recorded in millimetres immediately postoperative and after 4 months.

As it was not possible to compare bone heights for both groups as it is a case dependant, so percentage of bone loss was calculated at each group separately, then compared to each other.

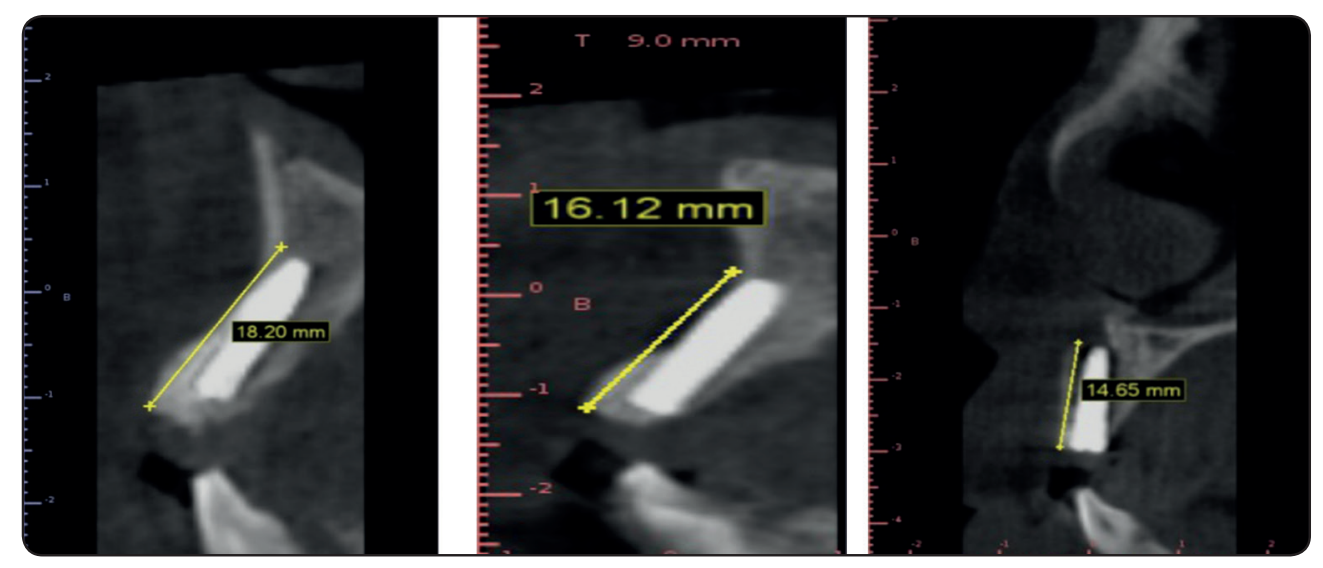

Fig. (2') CBCT images showing the labial bone heigh immediate postoperative. (patient number 2 in the control group) 


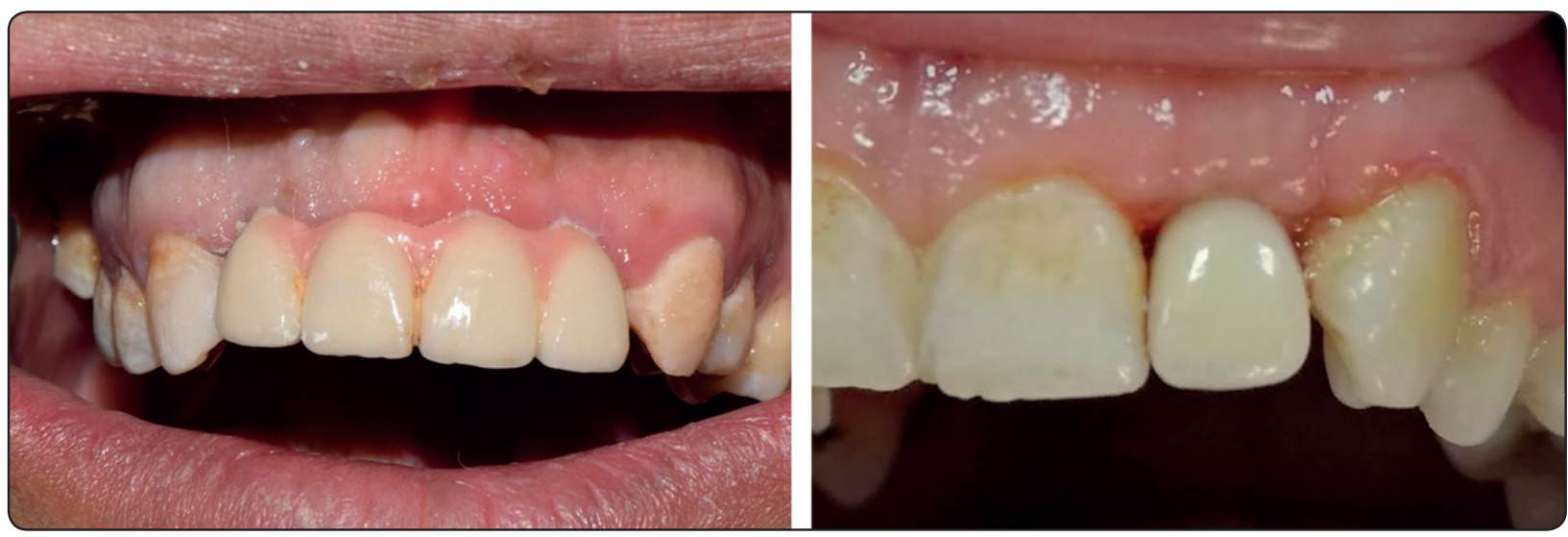

Fig. (4) Photographs showing the final prosthesis after cementation for patient number (2) in control group tooth number (22) (right image) and the final prosthesis after cementation for patient number (3) in the study group teeth number (12) and (22) (left image)

\section{RESULTS}

\section{Clinical data of the patients :}

The mean age of patients in Group (A) was $34.0 \pm 3.5$ years and ranged (28-40) while in Group (B) it was 39.7 \pm 13.0 years and ranged (29-61) This was statistically not significant; $\mathrm{P}=0.226$ Gender distribution in both Groups were 3 males and 6 females

\section{Clinical results of both groups :}

- Wound healing was uneventful in all patients without any signs of infection or wound dehiscence.

- Mild postoperative edema was noticed in all patients, which was completely resolved by the first recall visit at the first week.

-After 4 months from the immediate implant placement of both groups, the vertical height of the labial plate of bone was accepted for rendering immediate implants a bone preserving procedure in all patients.

-Implants exposure and healing collar placement after 4 months, then after two weeks impression for the implants and prosthesis delivery took place.

\section{Radiographic results of the two groups:}

\section{Vertical bone height:}

\section{a) Vertical bone height of control group:}

- The minimum immediate postoperative bone height was $10.37 \mathrm{~mm}$ and the maximum was $14.65 \mathrm{~mm}$ and had mean of 12.98 and1.69 (SD).

- The minimum 4 months postoperative bone height was $9.72 \mathrm{~mm}$ and the maximum was $13.95 \mathrm{~mm}$ and had mean 11.96 of and 1.6 (SD).

- The difference between immediate and four months postoperative control group was statistically significant $(p$ value $=0.001$ ). of

\section{b) Vertical bone height of study group :}

- The minimum immediate postoperative bone height was $10.37 \mathrm{~mm}$ and the maximum was 18.20 $\mathrm{mm}$ and had mean of $12.71 \mathrm{~mm}$ and 2.31 (SD).

- The minimum 4 months postoperative bone height was $9.86 \mathrm{~mm}$ and the maximum was $17.91 \mathrm{~mm}$ and had mean of 11.8 and 2.44 (SD).

- The difference between the immediate and four months postoperative of the study group was statistically significant ( $p$ value $<0.001$ ). 


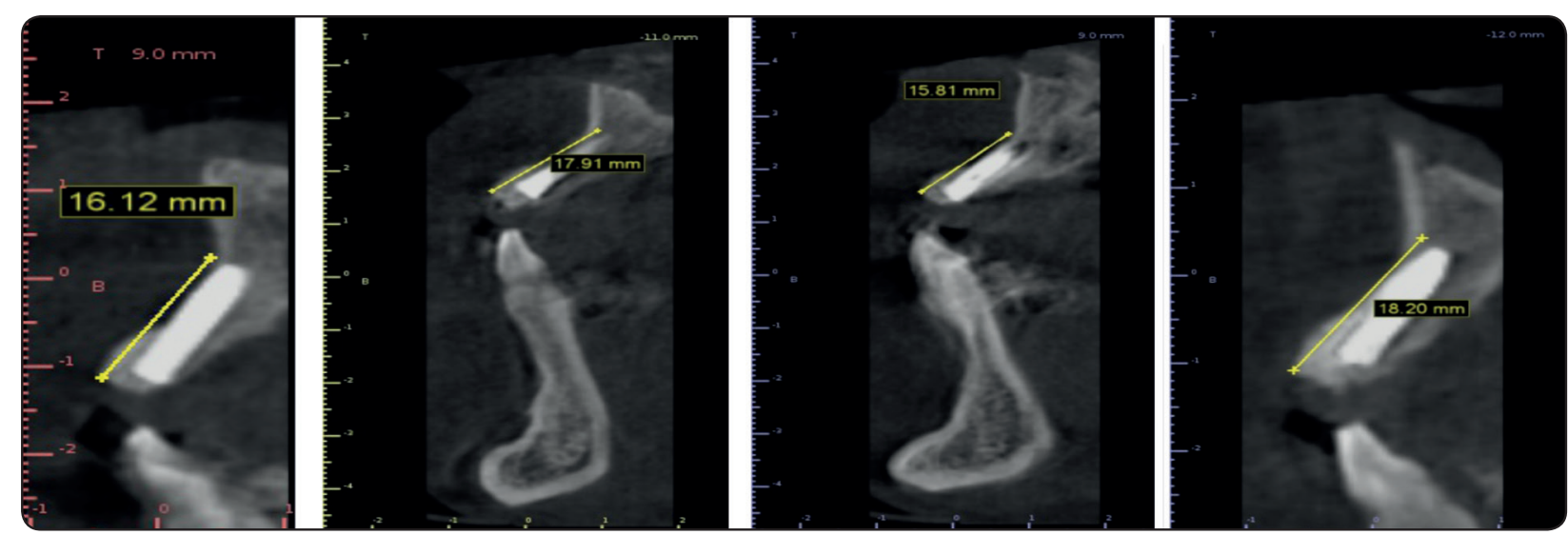

Fig. (7) CBCT image of study group (patient number 3) showing the bone height immediate postoperative (left images) and 4 months postoperative (right images)

Percentage of vertical bone loss in the two groups:

\section{Percentage of vertical height loss 4 months} postoperative between the two groups:

- The percentage of 4 months postoperative vertical bone loss of the control group was $7.8 \%$ and the standard deviation was 4.24.

- The percentage of 4 months postoperative vertical bone loss of the study group was $7.36 \%$ and the standard deviation was 3.16.

The difference between the percentages of four months postoperative bone loss between both groups was not statistically significant ( $p$ value $=0.807$ ).

\section{DISCUSSION}

Dental implants act as an artificial tooth roots and have been successful in preventing the physical and cosmetic problems that occur with tooth loss (Veis A et al 2010) $^{(7)}$. The long term survival of dental implants is evaluated by the amount of crestal bone loss around the implant (Prasad DK et al 2011) ${ }^{(\mathbf{8})}$. This peri implant crestal bone level and peri implant bone remodelling depends on the location of Implant Abutment Junction (IAJ) in relation to the crest of the bone and the amount of soft tissue coverage (Fickl S et al 2010) $)^{(9)}$.

Since early dental implant placement techniques, various modifications have been introduced to reach less invasive, faster and more esthetic ways to restore the missing teeth. One of these innovations was the development of immediate implant placement technique after extraction of the tooth, this has cancelled the need for waiting for the alveoli to heal which is the traditional technique. Immediate implant placement has the advantages of reduction of the numbers of surgical intervention, reduction of the overall treatment time (Schultz AJ 1993) ${ }^{(\mathbf{1 0})}$, improvement of implant orientation during its placement (Denissen HW et al 1993) ${ }^{(\mathbf{1 1})}$, improvement of esthetics of the surrounding soft tissue (Shanaman RH 1992) $)^{(\mathbf{1 2})}$ and preservation of the extraction area (Schwartz-Arad D et al 2000 ${ }^{(13)}$. Immediate implant placement in extraction sockets has high success rates (Cornelini R et al 2000) ${ }^{(14)}$.

Treatment planning is important in determining the reasons of tooth extraction. Reasons for tooth extraction may include insufficient crown to root ratio, remaining root length, periodontal attachment level, furcation involvement, periodontal health status of teeth adjacent to the proposed implant site, 
non restorable caries lesions, root fractures with large endodontic posts, root resorption, and questionable teeth in need of endodontic retreatment (Becker W et al 2000) ${ }^{(15)}$. Patients included in this study had a single or multiple teeth indicated for extraction and they didn't suffer from any systemic disease.

The present study was done to evaluate and compare the vertical bone loss in the labial aspect around immediately placed implants in fresh extraction socket by coral bone(Novocor plus ${ }^{\circledR}$ B\&B Dental Italy) in the study group and xenograft (Bio-Oss ${ }^{\circledR}$ Geistlich Pharma Switzerland) in the control group by using two piece implants((Dual ${ }^{\circledR}$ Titan Industries Egypt) to be placed in the anterior region .

The minimal surgical trauma in the present study decreased the risk of bone necrosis and allowed the bone remodeling process to occur. Atraumatic extraction of the tooth is one of the most important factors to achieve successful immediate implant placement as it aids in maintenance of the maximum amount of bone. Different methods can be used for atraumatic tooth extraction such as the use of periotomes, dental luxators, vertical root distractors and piezo-surgery (Wilson TG, Weber HP 1993) ${ }^{(16)}$.

In the present study the integrity of the socket was checked using the osteotomy probe for any perforation or dehiscence. The implant was placed bodily palatal in the extraction socket and beyond the socket base by at least $2 \mathrm{~mm}$ to attain primary stability which is verified by using torque wrench ratchet.The clinical procedure used in our clinical trial is that patients were called for follow up after 4 months to measure the amount of vertical bone loss of the residual labial plate of bone to show the amount of bone loss in the two groups (study and control groups).

The method of radiographic calculation of the final vertical loss in each group of this research was closely similar to(Mounir M. et al 2014) ${ }^{(\mathbf{1 7})}$ who depended on the linear measurements taken from cone beam C.T preoperative, immediate and
6 months postoperatively to assess percentage of marginal bone loss in ridge splitting technique with immediate implant placement in the deficient anterior maxillary alveolar ridges.

Our results showed that the amount of bone loss with the use of coral bone is slightly less than the amount of bone loss with the use of bovine xenograft, although there was no statistical significant difference between the two types of grafts, the use of coral bone grafts looks promising.

Pakenjad $\mathrm{M}$ et al $2017^{(18)}$ revealed a study on 20 patients (mean age 38.8 years) requiring tooth extraction in a total of 27 areas in the anterior maxilla. They used atraumatic flapless tooth extraction, implant placement with insertion of a graft (test group) or no material (control group) between the implant and the socket wall. Clinical and cone beam computed tomographic examinations were performed before implant placement (baseline), 24 hours after surgery and 4-6 months (T2) after implant placement, to assess the buccal plate height $(\mathrm{BH})$ and implant complications. No statistically significant differences occured in bone height measurements between the test and control groups. The study demonstrated that immediate implantation resulted in 1.30 and $1.66 \mathrm{~mm}$ reduction in buccal bone plate in the test and control groups, respectively. They concluded that immediate implantation in the extraction socket together with xenograft failed to prevent bone resorption. From that previous study we can learn that bone resorption is going to occur eventually, but the use of bone grafts as bovine xenograft or other types as the one we used in this study which is coral bone (marine xenograft) is to hopefully minimize the amount of bone resorption which occurs after tooth extraction and immediate implant placement.

Sandor GKB et al $2003^{(19)}$ performed a study on the use of coral granules in alveolar ridge preservation. This study included 21 patients, 12 females and 9 males. These patients had 48 
dentoalveolar defects, 17 in the anterior maxilla (group1) and 31 in the posterior maxilla and mandible (group 2). They were followed clinically and radiographically from 3-7 years. The results were that in group 1 the coral granules restored the ridge temporarily and over the course of follow up only 3 of the 17 sites had sufficient bone support for dental implant placement (17.6\%). In group 229 of the 31 sites had sufficient bone support for dental implant placement (93.5\%).The difference between group 1 and 2 was found to be statistically significant $(p<0.001)$ and These results are not in agreement with the results of our present study. The main difference between our study and this study is that in our study the extraction of the tooth was atraumatic while in this study the extraction site was subjected to violent trauma that may have resulted in tooth avulsion or fracture in the alveolar bone in addition to lacerations in the mucoperiosteum which have lead to impairment of the blood supply.

In a study done by (Calasans-Maia et al 2014) (20) on 20 adult volunteers aged(30-60 years) which included single tooth extraction. Tooth extraction was performed at the baseline. All sites were randomly allocated to two test groups (TG1: grafted using a new bovine xenograft, Osseus ${ }^{\mathrm{R}}$, and TG2: grafted using commercially available bovine xenograft-Bio-Oss $\left.{ }^{\mathrm{R}}\right)$. They were restored 3 months later. the results were that all inserted implants (10 in each group) were eventually integrated . after 6 months in the TG1, the mean value of new bone formation was $33.7( \pm 7.1)$, for CT was $32.3( \pm 8.9)$ and for the remaining biomaterial was $10.7( \pm 16.2)$. In the TG2 the mean value of new bone formation was $19.3( \pm 22.6)$, on the CT was $49.9( \pm 14.1)$ and of the remaining biomaterial was $22.6( \pm 7.9)$. They concluded that there is no statistically significant difference that was observed between TG1 and TG2 after 6 months $(\mathrm{P}>0.05)$, and both biomaterials afforded a more favorable implant position. These results are in agreement with the results of our present study.
Papa et al 2009(21) conducted a study on 34 patients in which a total of 47 sinus lifting procedures were done with the use of natural coral granules as osteoconductive material, the coral bone was mixed with platelet rich plasma and placed on the maxillary sinus floor and followed clinically, radiographically and histologically. The results were that sinus lifts were divided into two groups: group A was composed of sinus lifts that were performed with immediate implant insertion and group B was composed of sinus lifts where implant insertion was delayed for 12 months after sinus lift grafting. In group A they found that the mean crestal height changed from $14.28 \pm 0.75 \mathrm{~mm}$ (obtained with bone augmentation) to $13.6 \pm 1.1 \mathrm{~mm}$ after 6 month, where as for patients who underwent delayed implant placement (12 month later, group B), the mean crestal height varied from $14.27 \pm 0.75$ $\mathrm{mm}$ immediately after surgery to $11.68 \pm 1.36 \mathrm{~mm}$ 12 months later after surgery. They concluded that aragonitic calcium carbonate are encouraging for osteoregenerative potential resulting in tissue organization that allow mechanical stability and function similar to that of native bone. These results are in agreement with the results of our present study, as the use of coral granules as osteoconductive material in this study provided high success rates which was similar to the results of our study.

\section{CONCLUSION}

After comparing the results taken from both groups and comparing them to each other we conclude that Immediate post-extraction implant placement is a valid technique and preserves the bony structure and that the vertical height of labial bone is reduced obviously with coral bone or with xenograft materials although there is a low statistical significance for using coral bone grafting material. 


\section{REFERENCES}

1. Schulte W, Kleineikenscheidt H, Lindner K, Schareyka R. The Tübingen immediate implant in clinical studies. Deutsche Zahnarztliche Zeitschrift. 1978 May;33(5):348-59.

2. M. Esposito, M. G. Grusovin, I. P. Polyzos, P. Felice, and H. V. Worthington, "Interventions for replacing missing teeth: dental implants in fresh extraction sockets (immediate, immediate-delayed and delayed implants)," Cochrane Database of Systematic Reviews, vol. 8, no. 9, Article ID CD005968, 2010.

3. Demers C, Hamdy CR, Corsi K, Chellat F, Tabrizian M, Yahia LH. Natural coral exoskeleton as a bone graft substitute: a review. Bio-medical materials and engineering. 2002 Jan 1;12(1):15-35.

4. Scarano A, Piattelli A, Assenza B, Carinci F, Donato LD, Romani GL, Merla A. Infrared thermographic evaluation of temperature modifications induced during implant site preparation with cylindrical versus conical drills. Clinical Implant Dentistry and Related Research. 2011 Dec; 13(4):319-23.

5. Baghban AA, Dehghani A, Ghanavati F, Zayeri F, Ghanavati $\mathrm{F}$. Comparing alveolar bone regeneration using BioOss and autogenous bone grafts in humans: a systematic review and meta-analysis. Int Endod J. 2009;4:125-130.

6. Murugan R, Rao KP, Kumar TS. Heat-deproteinated xenogeneic bone from slaughterhouse waste: physico-chemical properties. Bulletin of Materials Science. 2003 Aug 1;26(5):523-8.

7. Veis A, Parissis N, Tsirlis A, Papadeli C, Marinis G, Zogakis A. Evaluation of peri-implant marginal bone loss using modified abutment connections at various crestal level placements. Int J Periodontics Restorative Dent. 2010; 30(6):609-17.

8. Prasad DK, Shetty M, Bansal N, Hegde C. Crestal bone preservation: a review of different approaches for successful implant therapy. Indian J Dent Res. 2011;22:317-23.

9. Fickl S, Zuhr O, Stein JM, Hurzeler MB. Peri Implant bone levels around implants with platform switched abutments. Int Jrnl of Oral and Max implants. 2010; 25:577-81.

10. Schultz AJ. Guided tissue regeneration (GTR) of nonsubmerged implants in immediate extraction sites. Pract Periodontics Aesthet Dent. 1993;52:59-65.

11. Denissen HW, Kalk W, Veldhuis HA, van Waas MA. Anatomic consideration for preventive implantation. Int J Oral Maxillofac Implants. 1993; 82:191-196.
12. Shanaman RH. The use of guided tissue regeneration to facilitate ideal prosthetic placement of implants. Int J Periodontics Restorative Dent. 1992;124:256-265.

13. Schwartz-Arad D, Gulayev N, Chaushu G. Immediate versus non-immediate implantation for full-arch fixed reconstruction following extraction of all residual teeth: a retrospective comparative study. J Periodontol. 2000;71:923-928

14. Cornelini R, Scarano A, Covani U, Petrone G, Piattelli A. Immediate one-stage postextraction implant: a human clinical and histologic case report. Int J Oral Maxillofac Implants. 2000;15:432-437.

15. Becker W, Becker BE, Ricci A, Bahat O, Rosenberg E, Rose LF, et al.A prospective multicenter clinical trial comparing one and two-stage titanium screw-shaped fixtures with one-stage plasma-sprayed solid-screw fixtures. Clin Implant Dent Relat Res 2000;2:159-65.

16. Wilson TG, Weber HP. Classification Of And Therapy For Areas Of Deficient Bony Housing Prior To Dental Implant Placement. Int J Periodontics Restorative Dent. 1993;13:451-9.

17. M. Mounir, G. Beheiri, W. El-Beialy (2014). Assessment of marginal bone loss using full thickness versus partial thickness flaps for alveolar ridge splitting and immediate implant placement in the anterior maxilla. Int. J. Oral Maxillofac. Surg. 43: 1373-1380.

18. Paknejad M, Akbari S, Aslroosta H, Panjnoush M, Hajheidary S. Effect of Flapless Immediate Implantation and Filling the Buccal Gap with Xenograft Material on the Buccal Bone Level: A Randomized Clinical Trial. Journal of Dentistry (Tehran, Iran). 2017 Nov;14(6):344.

19. Sàndor GK, Kainulainen VT, Queiroz JO, Carmichael RP, Oikarinen KS. Preservation of ridge dimensions following grafting with coral granules of 48 post-traumatic and post-extraction dento-alveolar defects. Dental Traumatology. 2003 Aug;19(4):221-7.

20. Calasans-Maia M,Resende R,Fernandes G,Calasans-Maia J, Alves AT, Granjeiro JM. A randomized controlled clinical trial to evaluate a new xenograft for alveolar socket preservation. Clinical oral implants research. 2014 Oct; 25(10):1125-30.

21. Papa F, Cortese A, Sagliocco R, Farella M, Banzi C, Maltarello MC, Pellegrini C, D’ Agostino E, Aimola P, Claudio PP. Outcome of 47 consecutive sinus lift operations using aragonitic calcium carbonate associated with autologous platelet-rich plasma: clinical, histologic, and histomorphometrical evaluations. Journal of Craniofacial Surgery. 2009 Nov 1;20(6):2067-74. 